\title{
Automated detection of basal icequakes and discrimination from surface crevassing
}

\author{
Thomas S. HUDSON, ${ }^{1,2}$ ๑ J Jonathan SMITH, ${ }^{2}$ Alex M. BRISBOURNE, ${ }^{1}$ Robert S. WHITE ${ }^{2}$ \\ ${ }^{1}$ NERC British Antarctic Survey, Cambridge, UK \\ E-mail:tsh37@cam.ac.uk \\ ${ }^{2}$ Bullard Laboratories, University of Cambridge, Cambridge, UK
}

\begin{abstract}
Icequakes at or near the bed of a glacier have the potential to allow us to investigate the interaction of ice with the underlying till or bedrock. Understanding this interaction is important for studying basal sliding of glaciers and ice streams, a critical process in ice dynamics models used to constrain future sea-level rise projections. However, seismic observations on glaciers can be dominated by seismic energy from surface crevassing. We present a method of automatically detecting basal icequakes and discriminating them from surface crevassing, comparing this method to a commonly used spectrumbased method of detecting icequakes. We use data from Skeidararjökull, an outlet glacier of the Vatnajökull Ice Cap, South-East Iceland, to demonstrate that our method outperforms the commonly used spectrum-based method. Our method detects a higher number of basal icequakes, has a lower rate of incorrectly identifying crevassing as basal icequakes and detects an additional, spatially independent basal icequake cluster. We also show independently that the icequakes do not originate from near the glacier surface. We conclude that the method described here is more effective than currently implemented methods for detecting and discriminating basal icequakes from surface crevassing.
\end{abstract}

KEYWORDS: crevasses, glacier geophysics, ice dynamics, seismology, subglacial processes

\section{INTRODUCTION}

Icequakes at or near the ice/bed interface of a glacier have recently been the subject of a number of studies (see Podolskiy and Walter (2016); Aster and Winberry (2017) and references therein). These icequakes, referred to herein as basal icequakes, are important because they provide the potential to elucidate the interaction of ice with the underlying till or bedrock. This interaction is important for constraining basal sliding in ice dynamics models, a significant but relatively poorly understood process that is critical in improving sea-level rise projections (Morlighem and others, 2010; Ritz and others, 2015).

However, detecting these basal icequakes can be challenging. Often, the amplitude of the seismic energy reaching seismometers on the glacier surface is close to the noise level. Even when basal events have significantly greater amplitude than the background noise, surface crevassing events often dominate over basal events. Given the potential number of detected events in a given time period (e.g. order of thousands per day (Mikesell and others, 2012; Röösli and others, 2014; Smith and others, 2015)), automated basal event detection and discrimination from surface crevassing is desirable. Here, we present the application of an automatic earthquake detection method, QuakeMigrate to this problem. QuakeMigrate automatically detects events that can then be further analysed to discriminate between surface crevassing and basal icequakes. This software has been made publicly available, and therefore the software combined with the details provided here will provide a useful and accessible tool for future cryoseismological investigations.

Various detection methods have previously been applied to search for basal icequakes. The two most common methods are: short-term-average to long-term-average (STA/ LTA) algorithms; and frequency spectrum-based methods. STA/LTA algorithms (e.g. Allen (1978); Withers and others (1998)) are commonly used in many passive seismological environments, triggering on individual stations but with no discernible relationship between other stations. For icequake detection, they have been applied in a number of instances (Carmichael and others, 2012; Thelen and others, 2013; Allstadt and Malone, 2014). However, STA/LTA algorithms alone are generally insensitive for discriminating between surface crevassing and basal events. Frequency spectrum-based methods can provide better discrimination between crevassing and basal icequakes, although they are generally less sensitive to events with a low signal to noise ratio (SNR), such as smaller basal icequakes. These methods have proven successful for initial icequake detection in several studies ( $\mathrm{O}^{\prime}$ Neel and others, 2007; Helmstetter and Garambois, 2010; Röösli and others, 2014; Helmstetter and others, 2015). However, further processing is generally required, such as manual inspection of events or additional filtering, and spectrum-based methods are often used in combination with cross-correlation template matching searches (Carmichael and others, 2012; Mikesell and others, 2012; Thelen and others, 2013; Allstadt and Malone, 2014) in an attempt to retrieve some of the previously missed lower-SNR events. A further method uses seismic waveform amplitudes (Jones and others, 2013). While the latter method may prove effective for locating crevassing events, it would rarely be possible to discriminate between crevassing and basal events using amplitude methods alone. In summary, none of the aforementioned methods provide automated detection of both lower-SNR and higher-SNR events while also discriminating for basal 
crevassing, without applying complex, time-consuming further processing steps. The method described in this paper provides a simple yet powerful way of overcoming these icequake detection challenges.

\section{Data}

The data used to demonstrate the QuakeMigrate method detailed in this study are from a network of 13 seismometers located on Skeidararjökull, an outlet glacier of Vatnajökull Ice Cap, SE Iceland. They were deployed from 9 June to 2 August 2014. The network configuration is shown in Fig. 1. The inner seven instruments use $4.5 \mathrm{~Hz}$ geophones with Reftek RT 130 data loggers and the outer six instruments are Guralp 6TD $30 \mathrm{~s}$ seismometers. All the instruments were initially buried at $\sim 4 \mathrm{~m}$ depth, although they had all melted out to the surface by the end of the deployment. The sampling rate of the instruments was $500 \mathrm{~Hz}$. This dataset is useful for testing automatic detection and discrimination of basal icequakes from crevassing as the glacier was moving at an average speed of up to $100 \mathrm{~m} \mathrm{a}^{-1}$ during the deployment and there is a crevasse field within and to the immediate south of the network. Figure 2 shows how much surface crevassing (red) is observed compared to basal icequakes (blue), and therefore highlights the basal icequake detection challenge posed by this dataset.

\section{DETECTION METHODS}

In order to demonstrate the benefits of the QuakeMigrate method over previous methods, we compare the
QuakeMigrate detection method to a spectrum-based method similar to that used in recent icequake studies (O'Neel and others, 2007; Helmstetter and Garambois, 2010; Röösli and others, 2014; Helmstetter and others, 2015). This comparative, literature inspired method involves several steps, including a dispersion filtering step and a template matching technique. While these steps could also be applied to the outputs from the QuakeMigrate method, we do not undertake this in our study in order to emphasise the usefulness of the QuakeMigrate method even without additional post-processing steps. Here we briefly describe the key attributes of each method and their specific application to the Skeidararjökull dataset.

\section{QuakeMigrate detection method}

Theory

An outline of the QuakeMigrate method is shown in Fig. 3. The method involves back-propagating the energy arriving at seismic stations, searching for the coalescence of energy from multiple stations in time and space, building on the method of Drew and others (2013). The QuakeMigratebased detection method is as follows. (1) The raw seismic signal at each station is band-pass filtered, (2) an STA/LTA algorithm applied to derive what we henceforth refer to as the onset function (see Fig. 3b). Peaks in these onset functions provide an approximation for the energy from a potential event arriving at the particular station. (3) The onset functions for each station are then combined, back-propagating the energy arriving at each station through time and space,

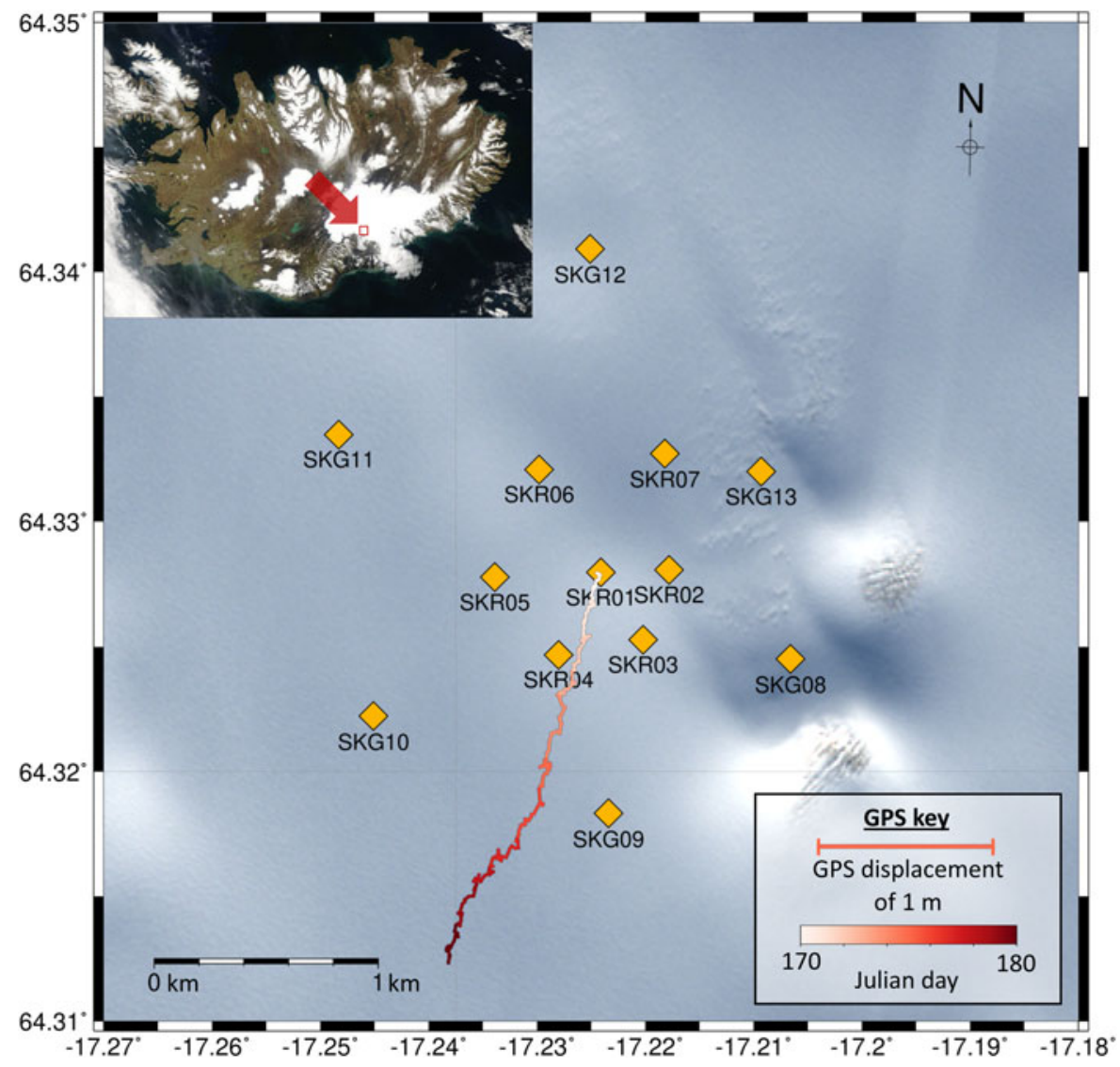

Fig. 1. Network of instruments used in this study. Inset satellite image shows location of the network in Iceland. A 7-day running mean GPS data for the instrument SKR01 is plotted, showing the relative location of the instrument through time, to indicate glacier flow direction ( SSW) (see key for scale). RGB background image of Skeidararjökull is Copernicus Sentinel 2B data 2017, processed by the European Space Agency (ESA). 


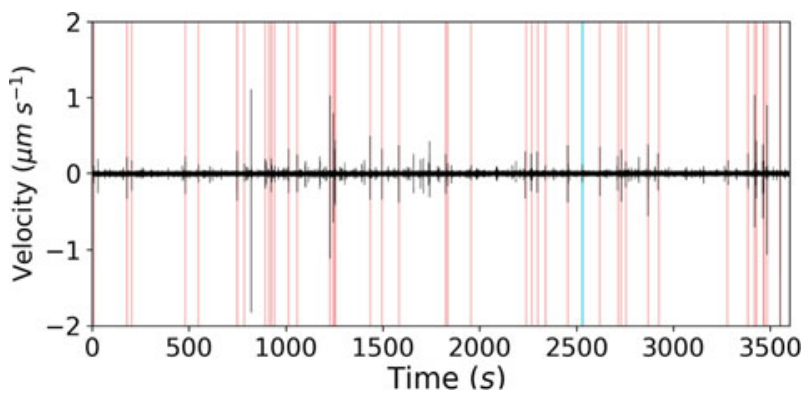

Fig. 2. Plot of 1 hour of data for the vertical component of station SKR01. Red lines indicate manually identified crevassing events, blue lines indicate basal events. The data are for 18:00-19:00 on 29 June 2014.

searching at each time step for any locations where peaks in the onset functions for multiple stations become aligned, or coalesce. The point of maximum coalescence represents the most likely source and origin time of seismic energy and therefore the event hypocentre. To back-propagate the onset functions through time and space, one has to specify the velocity of the medium. QuakeMigrate allows for homogeneous, $1 \mathrm{D}$ or $3 \mathrm{D}$ velocity models to be specified. Here, we use a homogeneous velocity model. (4) The time and space through which we back-propagate the seismic energy is gridded, with the coalescence of the onset functions at each grid node calculated for each time sample. (5) If the maximum coalescence value for a particular time step reaches a defined threshold, an event is detected. This threshold is chosen to be sufficiently high so as to minimise false triggers caused by noise. (6) The arrival times for the event are then calculated based on the associated individual onset function peaks, with the arrival time uncertainties calculated from the standard deviation of the onset functions.

(7) The final step in the icequake detection method is to locate the QuakeMigrate detected event hypocentres more accurately in order to spatially discriminate between surface crevassing and basal events. We use the non-linear hypocentre location method, NonLinLoc (Lomax and Virieux, 2000). NonLinLoc uses the phase arrival times and arrival time uncertainties found using QuakeMigrate to probabilistically locate the most likely hypocentre for a given event and provides estimates of the uncertainty in the location. It also accounts for uncertainty in the velocity model. We then filter the data using estimates of the maximum depth uncertainty, $\sigma_{z}^{2}$, and the RMS time residual $t_{\mathrm{rms}}$ (see Appendix A for further details). By this method, a catalogue of relocated basal icequakes and crevassing is obtained.

The underlying method of searching for events using the coalescence of energy described above is similar to the Coalescence Microseismic Mapping (CMM) method (Drew and others, 2013) used by Smith and others (2015) for the location of icequakes near the bed of the Rutford Ice Stream, West Antarctica. The CMM algorithm has been applied to our dataset and successfully detected a significant number of events. However, for several reasons, it proved ineffective at distinguishing between basal icequakes and crevassing. Firstly, the CMM method provides insufficient output to optimise the initial search parameters required to effectively separate real events from false triggers. Secondly, CMM is limited by the size of travel-time lookup table that can be used, therefore limiting the spatial resolution to search over, whereas QuakeMigrate does not have the same limitation. Thirdly, no uncertainties in the arrival times or the location are calculated, although these are required for better constrained relocated event hypocentres, for spatial filtering. Unlike the algorithm defined in Drew and others (2013), the QuakeMigrate method provides uncertainty estimates for both location and phase arrivaltimes. Figure $3 \mathrm{~b}$ shows the phase arrival time uncertainty estimated by QuakeMigrate for the P arrival at one station as the first standard deviation of the fitted Gaussian (shown by the red dashed line in the inset plot), with more details found in ?. These uncertainty estimates make the results considerably more useful because non-linear location methods, such as NonLinLoc (Lomax and Virieux, 2000), can then be used to more accurately locate potential events. Relocated event hypocentres, along with their associated depth uncertainties, can then be used to filter basal icequakes from surface crevassing. The optimal initial location of events is more pertinent in the case of Skeidararjökull compared to the Rutford Ice Stream as Skeidararjökull is considerably thinner, and therefore an overlap of hypocentre uncertainty regions of basal icequakes and surface crevassing hypocentres is far more likely.

\section{Setup for Skeidararjökull case}

The parameters for QuakeMigrate used in this study are given in Table 1. It is likely that these parameters are broadly applicable for the majority of basal icequake studies. However, the coalescence detection threshold specified in Table 1 is likely to depend on the network geometry and local noise levels.

\section{A spectrum-based detection method for comparison}

\section{Theory}

The spectrum-based method used for comparison in this study is outlined in Fig. 4. The method involves searching for peaks in the spectral power of a continuous trace over time, within a specific frequency band of the spectrum. Peaks in spectral power above a threshold trigger a potential event arrival at one station. Here we do this just for the vertical component and only trigger an event if it is detected on four or more stations concurrently.

This spectrum-based method with dispersive arrival filtering, detailed below, can provide an effective detection method in its own right, especially when combined with a cross-correlation template-based search using the initial events found, again detailed below. We therefore also make an implementation of this method (SpectDetect) publicly available.

\section{Event discrimination using dispersion measurement}

Due to the variability in the spectra of surface crevasse arrivals, some crevassing events have energy falling within the frequency band used to search for basal icequakes. Also, if a crevassing event is of sufficient amplitude, it is possible for it to trigger at four or more stations, resulting in an event detection. To remove this crevassing from the triggered icequake catalogue, we measure the frequency-time dispersion characteristics of event triggered arrivals at stations on horizontal components. Basal icequakes should not generate any surface wave energy, whereas crevassing events theoretically should exhibit strong surface wave arrivals that could be dispersive in nature (Aki and Richards, 2002). Although we use a 

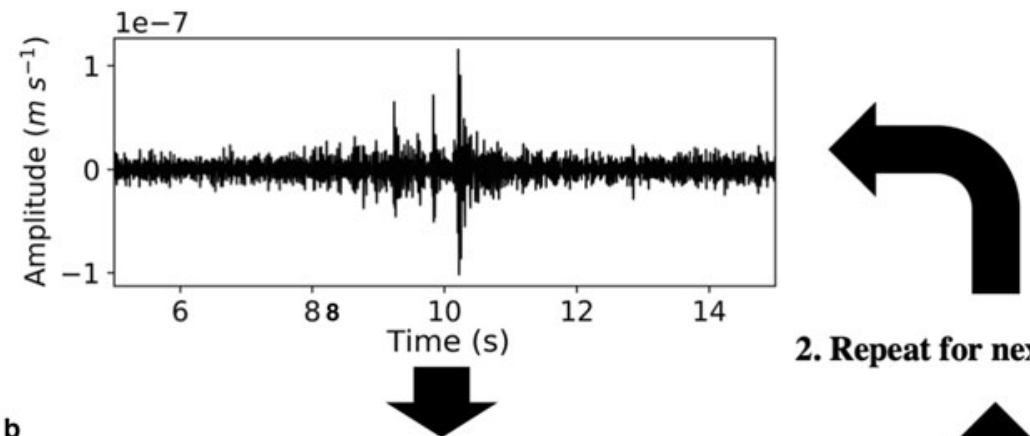

\section{Repeat for next station}
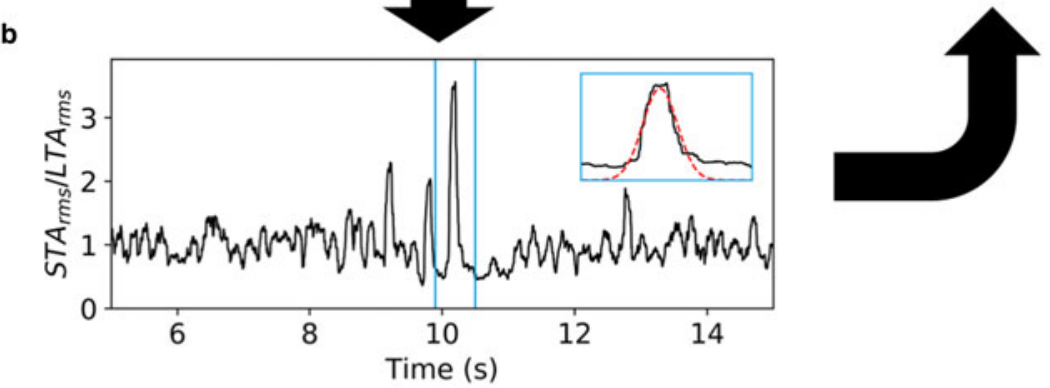

3. Search through time and space for coalescence of combined onset functions for all stations:
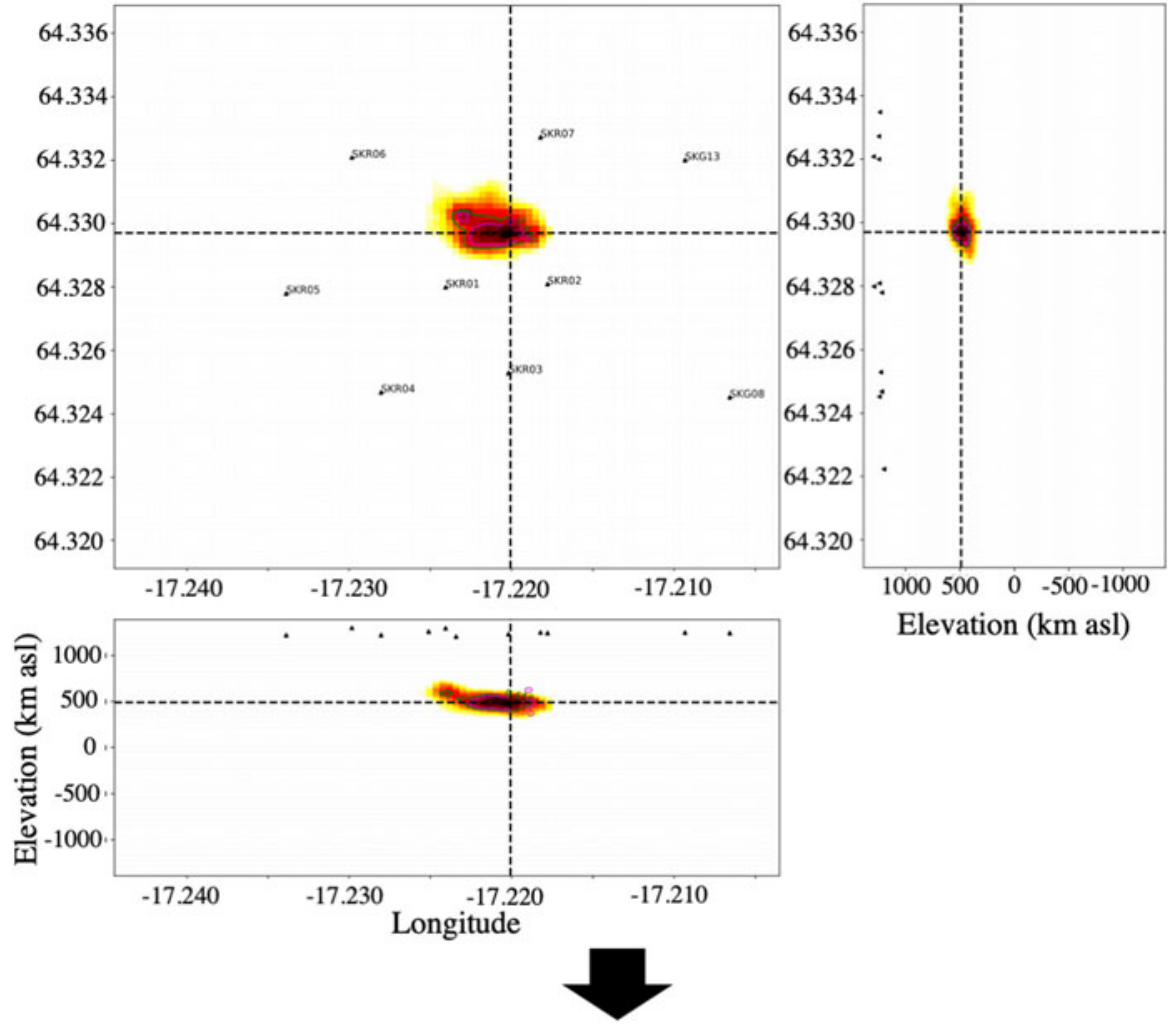

Elevation (km asl)

\section{If energy coalesces, trigger event detection}

Fig. 3. The QuakeMigrate detection method workflow for a triggered event. Arrows indicate the route through the various stages. (a) Filtered seismic trace for a single station. (b) The STA/LTA onset function. Inset plot in blue box shows a Gaussian function (red dashed line) fitted to the onset function, with the standard deviation assigned as the arrival time uncertainty. (c) The coalescence map for the event for the maximum coalescence time step, showing the coalescence of onset functions for all available stations.

homogeneous ice velocity model in this study for locating icequakes, we understand that in reality there is likely to be a velocity gradient with depth due to the presence of a firn layer, resulting in significant decreases in seismic velocity near the surface. This velocity gradient would cause dispersive crevasse surface waves. Any event arrivals that are clearly dispersive are neglected, hence producing a detected icequake catalogue containing fewer surface crevassing events.

The method used to measure the dispersion of an event arrival is based upon Frequency Time Analysis (FTAN) 
Table 1. Table of specific QuakeMigrate parameters used in this study

\begin{tabular}{ll}
\hline Parameter & \multicolumn{1}{c}{ Value } \\
\hline Frequency filter, P-wave & $20-120 \mathrm{~Hz}$ \\
Frequency filter, S-wave & $10-120 \mathrm{~Hz}$ \\
Seismic velocity, P-wave & $3630 \mathrm{~m} \mathrm{~s}^{-1}$ \\
Seismic velocity, S-wave & $1833 \mathrm{~m} \mathrm{~s}^{-1}$ \\
Grid resolution & $x=100 \mathrm{~m}$ \\
& $y=100 \mathrm{~m}$ \\
STA/LTA, P-wave & $z=20 \mathrm{~m}$ \\
STA/LTA, S-wave & $0.01 \mathrm{~s} / 0.25 \mathrm{~s}$ \\
Coalescence detection threshold & $0.05 \mathrm{~s} / 0.5 \mathrm{~s}$ \\
Moving time window (marginal window) & 1.4 \\
Pre/post padding around window & $0.75 \mathrm{~s}$ \\
NonLinLoc event relocation filter parameters: & $1.0 \mathrm{~s}$ \\
$\sigma_{z}^{2}$ & \\
$t_{\text {rms }}$ & $0.075 \mathrm{~km}^{2}$ \\
\hline
\end{tabular}

theory (Keilis-Borok, 1989). For each triggered event, we take the complete signal,

$$
W(t)=w_{\mathrm{r}}(t)+w_{\mathrm{c}}(t) i
$$

where $w_{\mathrm{r}}(t)$ is the real signal observed at a receiver and $w_{\mathrm{c}}(t)$ is the complex component of the signal, obtained by taking the Hilbert transform of the real signal. We then take the Fourier transform of $W(t)$,

$$
K(\omega)=F[W(t)]
$$

The FTAN domain, $S\left(\omega^{H}, t\right)$, can then be obtained by applying a filter, $G(\omega)$. A simple and effective choice of filter is a Gaussian filter (Keilis-Borok, 1989), with a centre frequency $\omega^{H}$ and a bandwidth $\sigma\left(\omega^{H}\right)$. For a given centre frequency, $\omega^{H}$,

$$
S\left(\omega^{H}, t\right)=F^{-1}[G(\omega) K(\omega)]
$$

One can then derive $S\left(\omega^{H}, t\right)$ for a range of $\omega^{H}$. The gradient of the peak in energy over the duration of a particular event arrival within this domain, $\left(\delta \omega^{H}\right) / \delta$, provides a measure of the dispersion of the event arrival. The event arrival is dispersive if $\left(\delta \omega^{H} / \delta t\right)>0$. This is undertaken automatically, with the event removed from the catalogue if $\left(\delta \omega^{H} / \delta t\right)>0$.

The phase arrivals of all the detected events are manually picked and located using NonLinLoc (Lomax and Virieux, 2000), as with the QuakeMigrate method. The catalogue of located events are then filtered using the $\sigma_{z}^{2}$ values calculated by NonLinLoc.

\section{Cross-correlation template-based search}

A cross-correlation template-based search is used to find more events. Deep icequake events initially found using the spectrum-based method are used as template events, which are cross-correlated with continuous data, in order to find more, similar events. The signals from a template icequake arriving at each station are individually cross-correlated with the continuous data for each corresponding station. Here, we only perform this on the vertical component of each station. A cross-correlation detection threshold is set, with an event detected if the cross-correlation coefficient between the template and the continuous data for the same window is greater than the threshold. In this case we use a

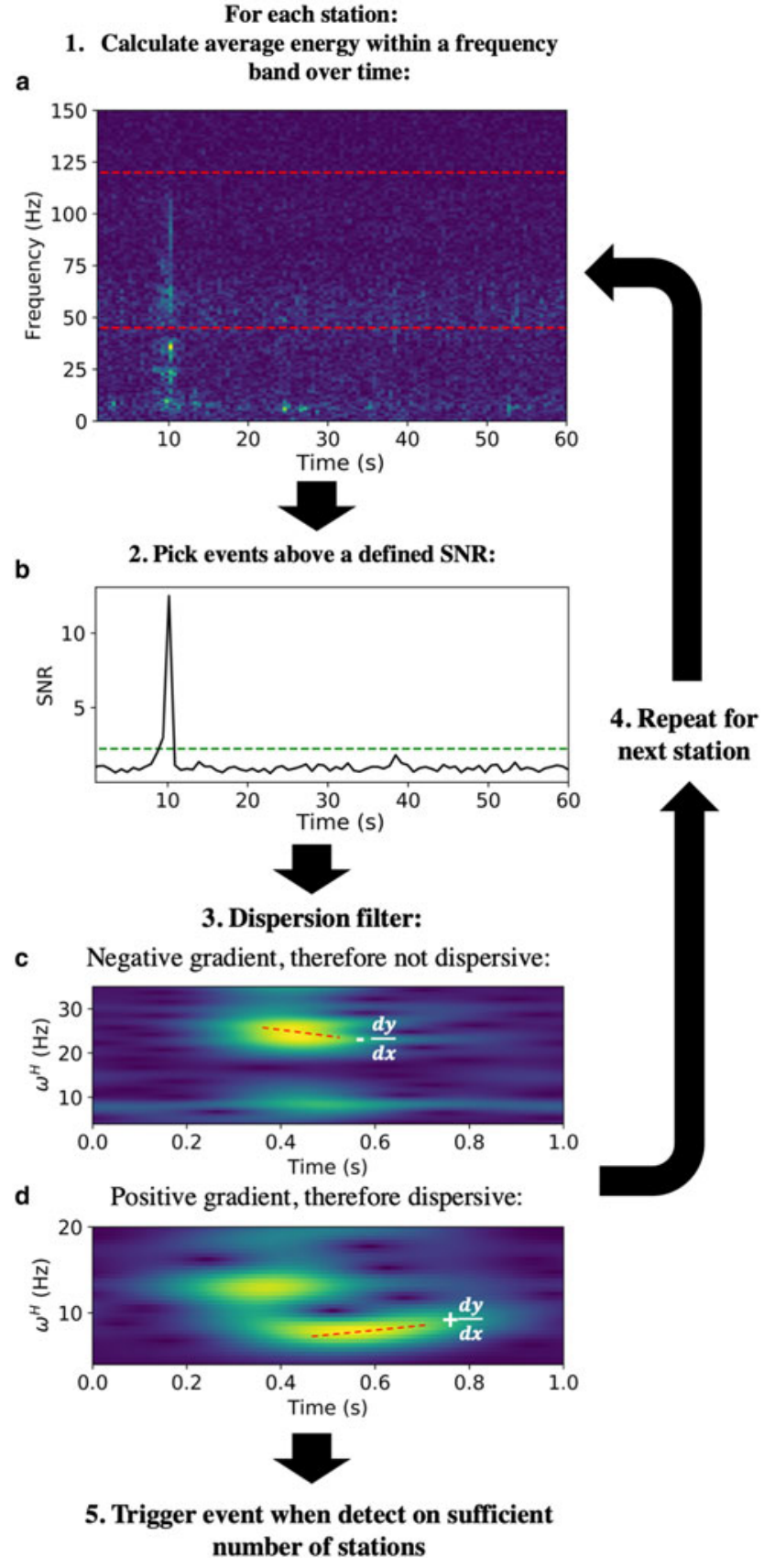

Fig. 4. The spectrum-based detection method workflow. Arrows indicate the route through the various stages. (a) Spectrogram of seismic trace. (b) SNR over time for the average energy of seismic energy within a defined frequency band (shown by the red dashes in (a)). (c) Example of FTAN space for an event arrival that is not dispersive at a station. (d) Example of FTAN space for an event arrival that is dispersive at a station. $\omega^{H}$ is centre frequency.

value of 0.7. The cross-correlation method therefore detects previously undetected events that are similar to the template event and therefore likely to come from the same approximate location.

\section{Setup for the Skeidararjökull case}

The parameters used in the spectrum-based search are given in Table 2. The high-pass filter value of $45 \mathrm{~Hz}$ is above the high-pass filter value used in the QuakeMigrate run. This difference is due to the insensitivity of the spectrum-based detection algorithm to surface crevassing, even with the 
Table 2. Table of specific spectrum-based method parameters used in this study

\begin{tabular}{ll}
\hline Parameter & \multicolumn{1}{c}{ Value } \\
\hline Detection frequency window & $45-120 \mathrm{~Hz}$ \\
Spectrogram time window duration & $1.0 \mathrm{~s}$ \\
Minimum detection SNR & 2.5 \\
Minimum number of stations to trigger & 4 \\
Dispersion filter parameters: & \\
Centre frequency $\left(\omega^{H}\right)$ range & $4.0-120 \mathrm{~Hz}$ \\
$\Delta \omega^{H}$ & $0.5 \mathrm{~Hz}$ \\
Gaussian filter bandwidth & $1.25 \mathrm{~Hz}$ \\
\end{tabular}

dispersion filter implemented. A value of $45 \mathrm{~Hz}$ is sufficiently high that P-wave arrivals from surface crevassing are unlikely to be detected at four or more stations. The parameters used here are likely to be generally applicable for icequakes in other environments, but the limitation of the lower frequency window limit value might mean that lower frequency basal icequakes go undetected.

\section{RESULTS}

To test the effectiveness of QuakeMigrate compared to common icequake detection methods reported in the literature, we present results on the performance of the QuakeMigrate detection method for the seismic network deployed at Skeidararjökull, independently confirm that the detected deep icequakes are indeed approximately basal in origin and compare the effectiveness of the QuakeMigrate method to the spectrum-based method. Finally, we present results from the Rutford Ice Stream, Antarctica, in order to demonstrate how QuakeMigrate performs in a less noisy environment.

\section{Skeidararjökull icequake detection}

\section{Performance of the QuakeMigrate detection method}

The best measures of performance of the QuakeMigrate detection method are the number of true basal icequake detections compared to the number of surface crevassing events incorrectly identified as basal icequakes; and the actual number of basal icequakes detected. Icequake detections over a period of 5 days from 25 to 29 June 2014 are used to assess this performance. These results are plotted in Fig. 5. We manually picked the phase arrivals associated with all events initially detected using QuakeMigrate that, when relocated using NonLinLoc, had hypocentral depths $\sim 200 \mathrm{~m}$ below the ice surface (i.e. below $1 \mathrm{~km}$ asl).

Of the 134 events deeper than $200 \mathrm{~m}$ below the ice surface, it was possible to manually pick $\mathrm{P}$ and $\mathrm{S}$ phase arrivals for 65 events. Of these, only 50 events met the NonLinLoc relocation quality measures we imposed on the original QuakeMigrate data (see Appendix A). Approximately $50 \%$ of these events remained deep after relocation, locating closer to the ice/bed interface than the surface, as shown by the blue points in Fig. 5 .

\section{Confirmation that basal icequake sources are not in the near surface}

Although a number of events detected by QuakeMigrate locate near the ice/bed interface, here we also use other metrics to confirm whether these icequakes are indeed of basal origin. Figure 6 shows some of the metrics used, comparing basal and surface crevassing events. Various parameters for the three events are plotted. The first event is a high SNR basal icequake, detected by both the QuakeMigrate and spectrum-based methods. The second event is a low SNR basal icequake, detected by the QuakeMigrate method only. The third event plotted in Fig. 6 is a surface crevassing event, for comparison. The analysis of the icequakes presented in Fig. 6 is shown here primarily to show that QuakeMigrate is indeed detecting deep icequakes, and illustrate how one can more rigorously differentiate between deep icequakes and surface crevassing.

The waveforms for the $\mathrm{Z}, \mathrm{N}$ and $\mathrm{E}$ components are plotted in Fig. 6a, showing that all the arrivals are impulsive in nature, with the S-wave arrivals (indicated by the blue lines) initially appearing similar to the surface wave arrivals associated with the crevassing event (indicated by the gold lines). This similarity leads to potential uncertainty when using $\mathrm{P}$ and $\mathrm{S}$ phase arrivals to deduce whether an event is basal in origin. Particle motions at a receiver reduce this ambiguity, with the basal icequakes exhibiting clear linear particle motions for the $\mathrm{P}$ and $\mathrm{S}$ arrivals (Fig. 6b). The surface crevassing event, however, exhibits an elliptical motion for the surface wave arrival, suggesting that the arrival is indeed associated with a Rayleigh wave phase from a near-surface event. The $V_{\mathrm{p}} / V_{\mathrm{s}}$ and $V_{\mathrm{p}} / V_{\text {surface }}$ ratios shown by the Wadati plots (Wadati, 1933) (Fig. 6c) also suggest that the picked phase arrivals are associated with realistic $V_{\mathrm{p}}, V_{\mathrm{s}}$ and $V_{\text {surface }}$ values.

The frequency domain can also be used to confirm that the basal icequakes originate within or below the bulk ice and do not have any associated surface wave arrivals. Spectrograms show that the basal icequakes have higher frequency arrivals associated with the P-wave. FTAN style plots (Keilis-Borok, 1989) for the east component (Fig. 6e) show that the $\mathrm{S}$ wave arrivals for the basal icequakes do not demonstrate dispersive wave packet arrivals, whereas the surface crevassing event has a dispersive arrival on the horizontal components, indicated by $(\delta f / \delta t)>0$ (manually determined and indicated by the red dashed line on Fig. 6e). Since surface wave propagation can be dispersive, with an appropriate velocity-depth profile, this further points to the source of the third event interacting with the near surface.

Overall, the data presented in Fig. 7 confirm that the basal icequakes detected by QuakeMigrate are not associated with surface crevassing.

\section{Comparison of QuakeMigrate and spectrum-based detection methods}

Figure 7 and Table 3 compare results from the QuakeMigrate detection and spectrum-based methods.

QuakeMigrate detects more than four times the number of basal icequakes than the spectrum-based method (Table 3). When including additional events detected using a crosscorrelation search with template events detected via the spectrum-based method, QuakeMigrate still detects more than twice as many events.

The primary reason for QuakeMigrate detecting more events is because it is generally more sensitive than the spectrum-based method. It not only triggers an event using detectable energy at each station but also includes energy that might not otherwise be detectable from the noise at other 

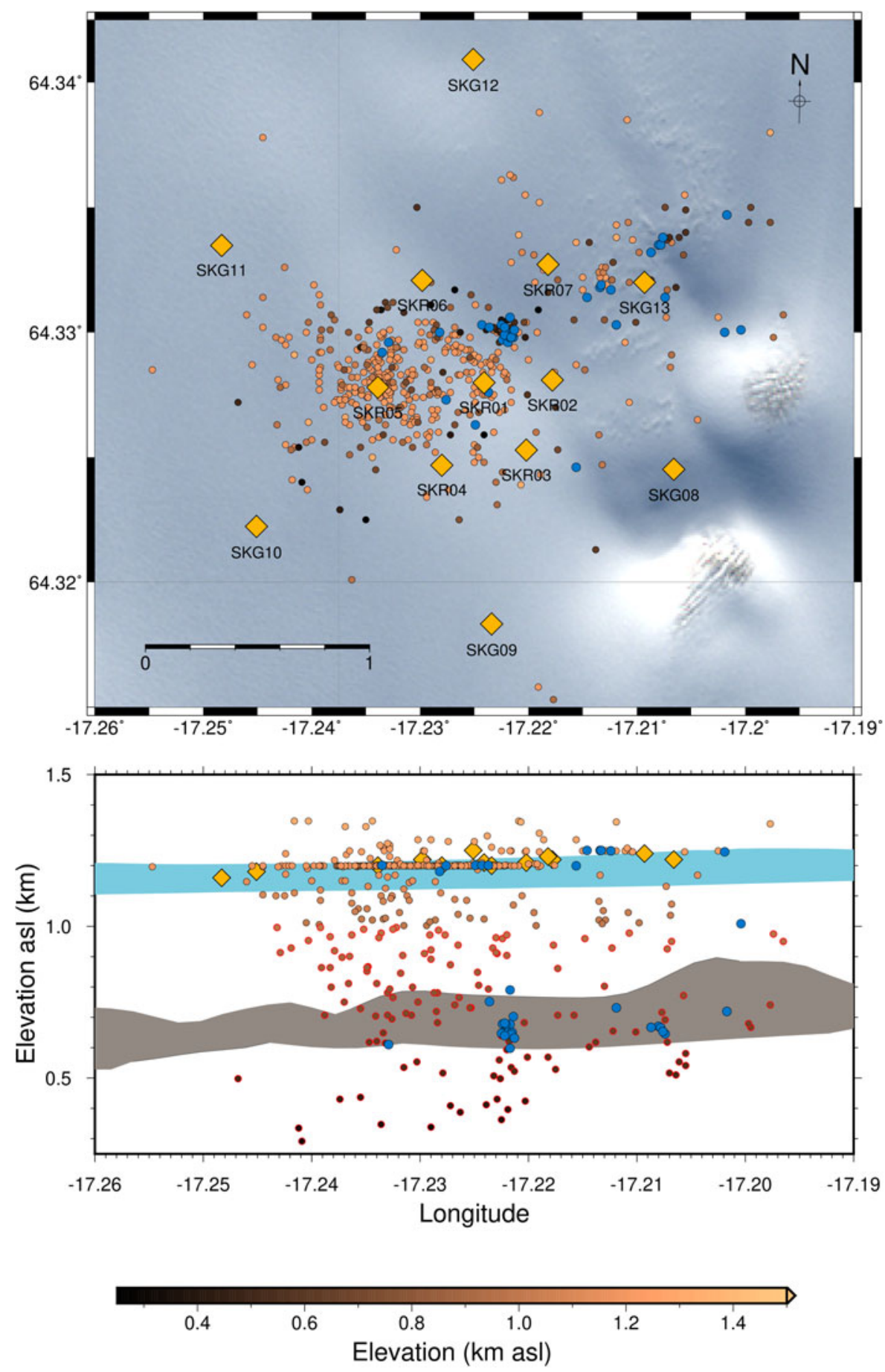

Fig. 5. Plot of icequakes detected via the QuakeMigrate method from 00:00 on 25 June to 23:59 on 29 June 2014 . All events below $1.0 \mathrm{~km}$ asl that have a sufficiently high SNR have their phase arrival times manually picked. Points coloured by the bronze colour scale are events with automatically picked P and S phases via the QuakeMigrate method, with the points with red outlines in depth cross-section being the automatically detected icequake hypocentres from which phases have been manually picked, and blue points are the relocated events using manually picked P and S phases. Gold diamonds are seismometers. The ice surface and bed topography between profiles from the far south and north of the map extent are indicated by the blue and grey shaded regions, respectively. These regions are defined from radar data, with the profiles provided by the Glaciology Group, Institute of Earth Sciences, University of Iceland (Björnsson, 2017).

stations and coalesces the energy from these stations too. Therefore, otherwise undetectable energy contributes to QuakeMigrate detections, making it more likely to detect a lower SNR event. Different detection thresholds are used for the QuakeMigrate and spectrum-based detection methods. Whilst best efforts were made to reduce these thresholds as much as possible, in an attempt to detect the maximum possible number of events, differences between the sensitivity of the two methods may result.
Detection thresholds are also relevant for the discussion of incorrect identification of surface crevassing events by both methods. The incorrect-event-identification-rate is the proportion of surface crevassing events incorrectly identified as basal icequakes detected relative to the total detections of each method. The incorrect-event-identification-rates are given in Table 3. Reducing detection thresholds inevitably increases incorrect-event-identification-rates. However, the QuakeMigrate false detection rate is comparable to 

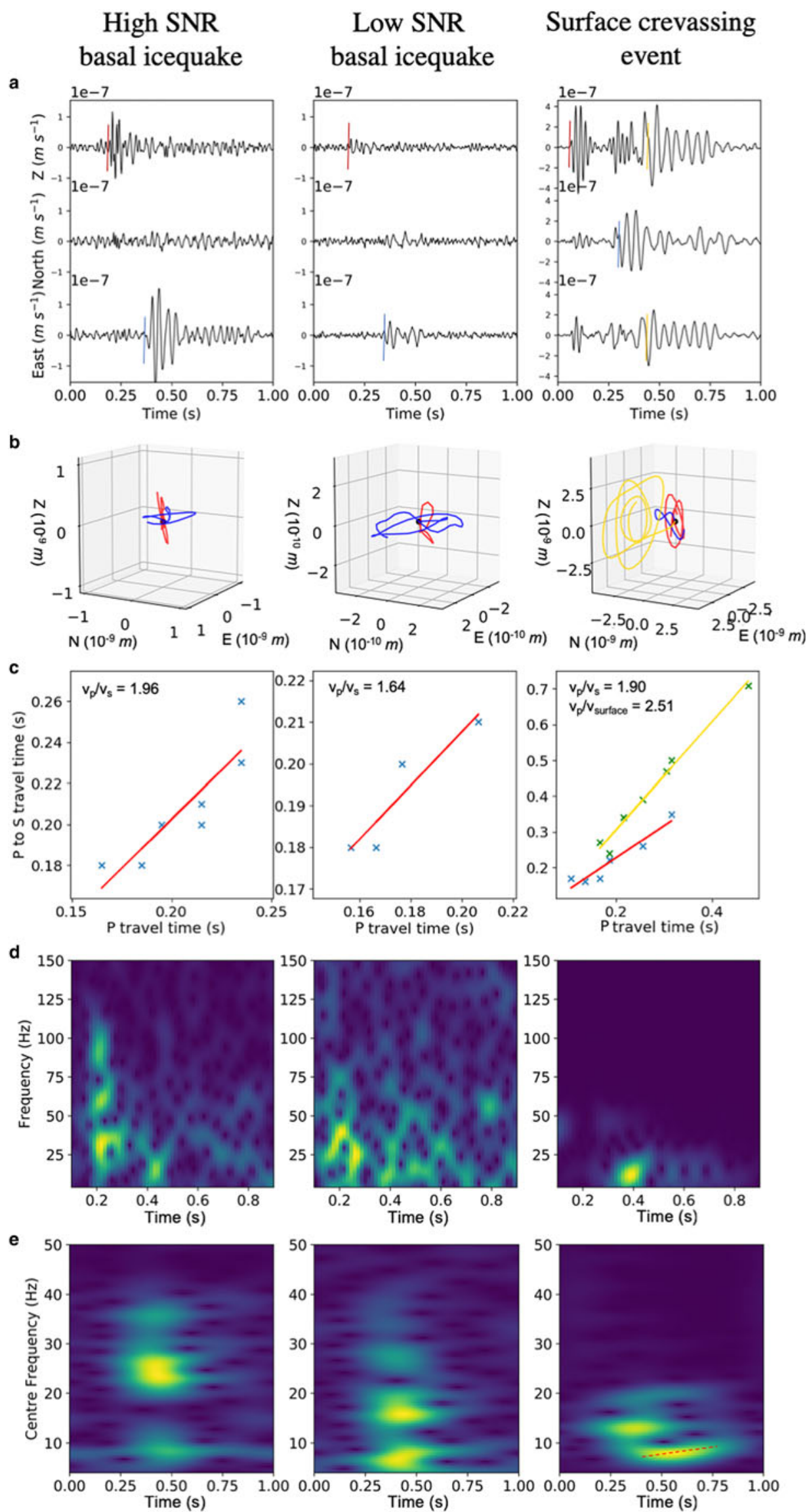

Fig. 6. Comparison of cleaner and noisier basal icequakes to a surface crevassing event. (a) Waveforms on the vertical, north and east components for each event at station SKR01. Manually picked phase arrivals are shown (red for P, blue for S, and gold for surface phases). (b) Particle motion for P (red), S (blue), and surface (gold) phase arrivals. (c) Wadati plots for each event (Wadati, 1933). The surface crevassing event has both P-S and P-surface phase data plotted. (d) Spectrograms for the vertical component, for each event. (e) FTAN space plots of centre frequency vs. time period, for the radial component. 

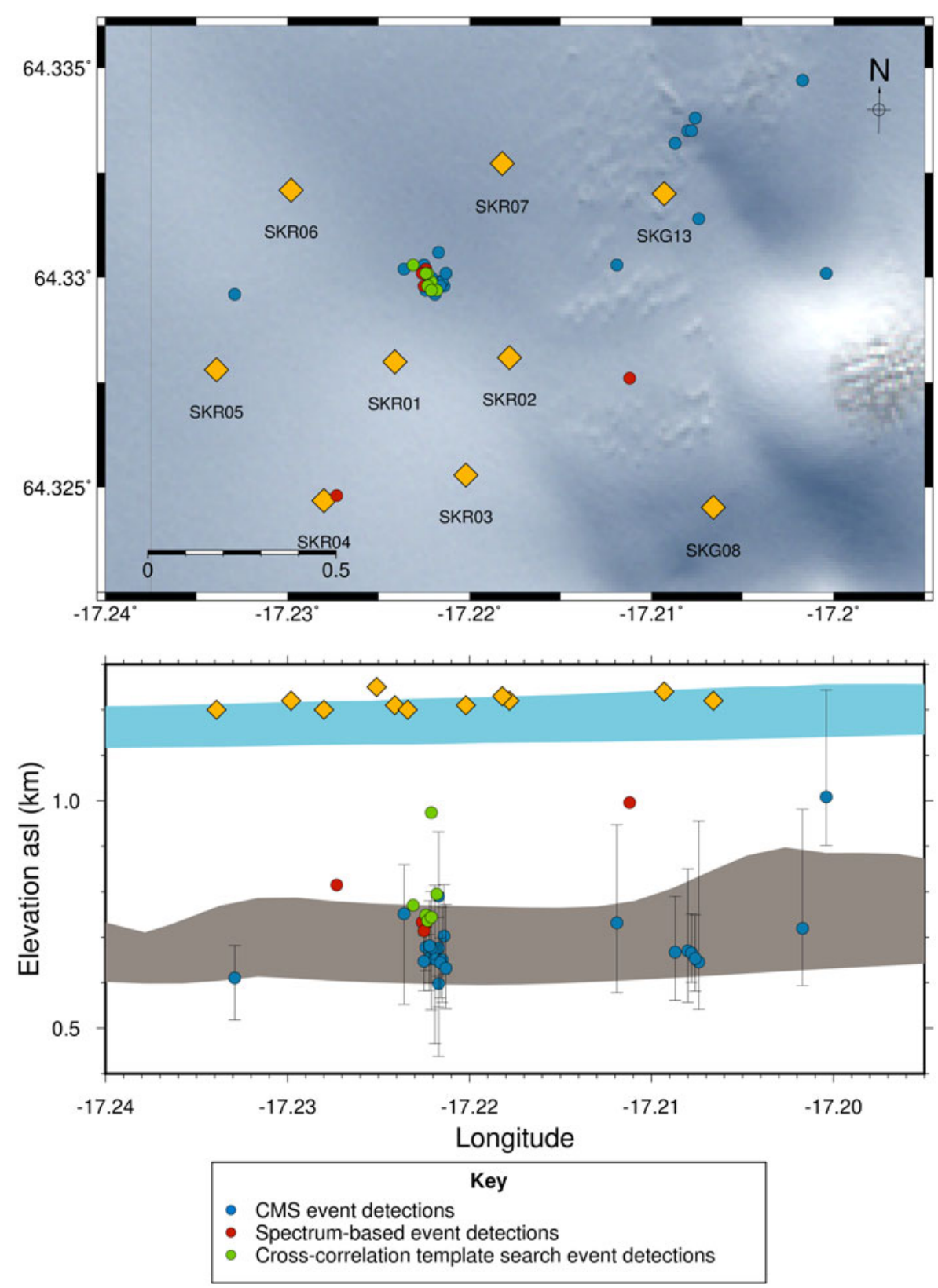

Fig. 7. Plot of manually picked and relocated icequakes that initially had hypocentres below $1.0 \mathrm{~km}$ asl from the QuakeMigrate and spectrumbased detection methods. Events detected via the QuakeMigrate method are plotted in blue, with their associated depth uncertainties. Events detected via the spectrum-based method are shown in red. Additional events detected via cross-correlation template matching from the spectrum-based method detected events are shown in green. Gold diamonds are seismometers. The ice surface and bed topography are as specified in Fig. 5.

microseismic detection methods in other environments such as volcano seismology (e.g Dixon and others (2005)). It is also worth noting that neither detection method triggers off random, stochastic energy arrivals at single stations but rather from other physical events such as surface crevassing or volcanic activity. It is likely that we would observe fewer incorrect event identifications at a different site where the activity of other seismic sources is lower.

QuakeMigrate detects multiple clusters of basal icequakes, whereas the spectrum-based method only identifies one clear cluster. This is a significant positive result for QuakeMigrate over the spectrum-based method since although a greater number of detected events alone provides a better temporal resolution of seismicity, the observation of multiple clusters can potentially enable investigations of a wider range of glaciological questions. For example, one could investigate the distribution of possible 'sticky' spots on the glacier bed, and possible corresponding topographical highs, hydrological systems or other factors. The cross-correlation template search does not provide any improvement on the spectrum-based search in this regard since the highly similar events found by the cross-correlation method are unlikely to be highly similar across multiple spatial locations.

One final comparative result is that not all the events detected by the spectrum-based method are detected by QuakeMigrate. This could be due to several reasons. Firstly, the QuakeMigrate method requires the overall energy arriving at a number of stations to be above the coalescence threshold, whereas the spectrum-based 
Table 3. Table summarising comparative performance metrics of the QuakeMigrate and spectrum-based methods, as well as the cross-correlation (CC) method applied to events detected via the spectrum-based method. The incorrect-event-identification-rate is defined as the number of surface crevasse events incorrectly identified as basal icequakes, relative to the total number of detections of crevassing and basal icequakes

\begin{tabular}{llll} 
& \multicolumn{1}{c}{$\begin{array}{c}\text { QuakeMigrate } \\
\text { method }\end{array}$} & $\begin{array}{c}\text { Spectrum- } \\
\text { based } \\
\text { method }\end{array}$ & $\begin{array}{c}\text { CC } \\
\text { method }\end{array}$ \\
\hline $\begin{array}{l}\text { Incorrect-event- } \\
\text { identification-rate: }\end{array}$ & $80 \%$ & $97 \%$ & $0 \%$ \\
$\begin{array}{l}\text { Number of basal ice- } \\
\begin{array}{l}\text { quake detections } \\
\text { (manually confirmed): }\end{array}\end{array}$ & $\begin{array}{c}\text { (in 2 clusters) } \\
\text { (in 1 cluster) }\end{array}$ & 6 & \\
\hline
\end{tabular}

method simply requires detectable energy to be observed at four stations. This means that the spectrum-based method could be more sensitive than QuakeMigrate in certain instances, such as where four stations may have a detectable signal, but noise on other stations inhibits QuakeMigrate from finding a sufficient coalescence of energy for a detection. Here, the spectrum-based method would still detect an event. A second reason could be that the spectrumbased method is more easily applied over a large range of frequencies, especially higher frequencies. It could be that QuakeMigrate is missing certain events because of the frequency-dependence induced by the STA/LTA onset function values. Another potential reason could be that there is possible overlapping in time between some basal events and surface crevassing. However, this last reason is unlikely for most events since it was possible to manually pick phase arrivals for events detected using the spectrum-based method.

Overall, although QuakeMigrate misses some basal events that the spectrum-based method detects, according to our metrics QuakeMigrate performs better than the spectrum-based method, having a higher detection rate, a lower incorrect-event-identification-rate, and detects additional, spatially independent clusters of activity that would otherwise be absent from our icequake event catalogue.

\section{Rutford Ice Stream icequake detection}

The challenging nature of the Skeidararjökull dataset, with low SNR basal icequakes is hypothesised to because of the geographical location. Skeidararjökull has high surface snow accumulation and ablation rates at the deployment site, leading to the poor coupling between the seismometers and the glacier. It is also a temperate glacier, likely resulting in higher attenuation than if the entire ice column were well below the ice melting point. The glacier moves at $<100 \mathrm{ma}^{-1}$, a slower speed than many other glaciers studied seismologically.

To investigate whether this does indeed affect the performance of QuakeMigrate, we also apply the QuakeMigrate method to data from Rutford Ice Stream, West Antarctica (Smith and others, 2015). Figure 8 presents the results. The results are similar to the earlier analysis of Smith and others (2015), as expected. We detect over 1000 events over a period of 2 days, with the majority of events located near the ice/bed interface (Fig. 8). The Rutford Ice Stream moves four times faster than Skeidararjökull, at $377 \mathrm{~m} \mathrm{a}^{-1}$ (Murray and others, 2007). The site of the network on the ice stream surface is within the accumulation zone, so the instruments remain well coupled to the glacier for longer. Furthermore, the Rutford Ice Stream is significantly thicker than Skeidararjökull, making it easier to discriminate between surface and basal events. There are also fewer crevasses, resulting in fewer surface crevassing events to discriminate from basal icequakes. These data, therefore, demonstrate the potential performance of QuakeMigrate on a higher SNR data than the Skeidararjökull dataset.

\section{DISCUSSION}

\section{Application of QuakeMigrate for basal icequake detection: advantages}

Our results show that QuakeMigrate can be used as an effective tool for basal icequake detection. Although spectrumbased and other icequake detection methods have proven effective in certain instances, our results show that for a glacier with significant surface crevassing noise, QuakeMigrate outperforms the spectrum-based method in discriminating basal from near-surface icequakes. There are a number of advantages. The higher number of basal icequake detections provides a better spatial and temporal understanding of icequake activity. It detects greater numbers of events even than a cross-correlation template search in addition to the spectrum-based method. The lower rate of incorrect event identifications using QuakeMigrate reduces the time taken to produce a basal icequake catalogue from a dataset dominated by noise, or by surface events.

There are several reasons why QuakeMigrate is significantly more effective than other icequake detection methods. Firstly, QuakeMigrate triggers event detections based upon coalescence of both $\mathrm{P}$ and $\mathrm{S}$ energy arriving at multiple stations. This allows for more effective discrimination of surface crevassing events than for other methods since the energy from crevassing is dominated by dispersive surface waves, whose energy in the time domain appears more dispersed and therefore coalesces more weakly. The body waves are also attenuated over length scales smaller than that of the seismic network used in this study, likely due to a firn layer, and increased water content and fractured ice near the glacier surface. It is, therefore, less likely that one would obtain a high coalescence of energy for a crevassing event compared to a basal event at the same distance, although some crevassing events are still of sufficiently large amplitude to coalesce above the detection threshold. Secondly, QuakeMigrate is effective because it provides a physically rigorous estimation of phase arrival time uncertainty. These arrival time uncertainties can be used in hypocentre relocation by NonLinLoc, resulting in better hypocentral locations and more reliable estimations of the associated uncertainty metrics calculated by NonLinLoc, for example $\sigma_{z}^{2}$, a measure of uncertainty in depth, and $t_{\mathrm{rms}}$ a measure of the overall residual timing error associated with an event. The more accurate hypocentral locations and their associated uncertainties can be used to more effectively filter the data to reduce the number of incorrect event identifications (see Appendix A for further details). QuakeMigrate also likely detects more events than the spectrum-based method because it can be applied using wider 

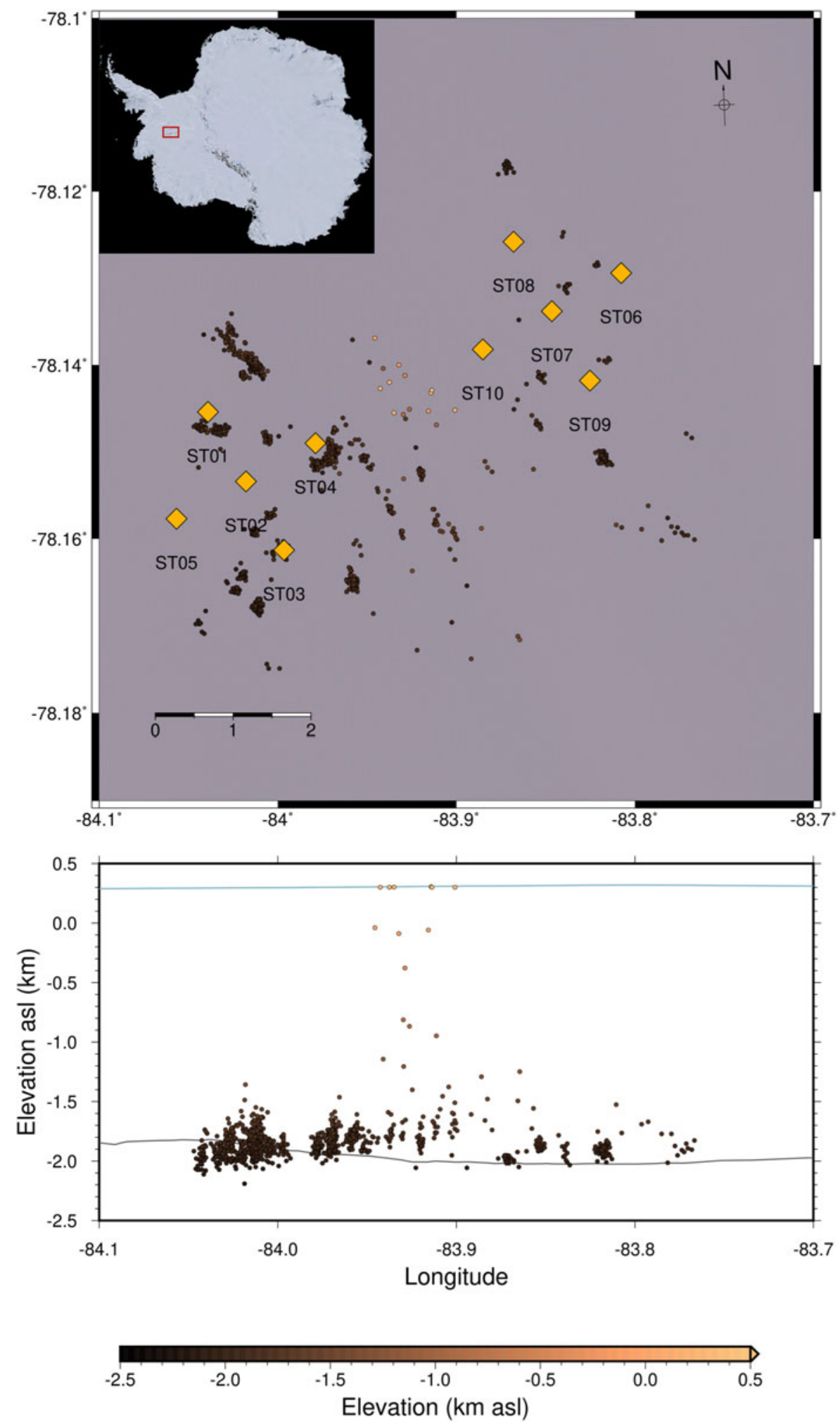

Fig. 8. Plot of QuakeMigrate detected icequake hypocentres at the Rutford Ice Stream, Antarctica, for the 20-21 January 2009. All events detected are relocated using NonLinLoc. The ice surface and ice/bed interface are indicated by the blue and grey lines, respectively (King and others, 2016). The RGB background image is Copernicus Sentinel 2A data 2016, processed by ESA. Inset satellite image of Antarctica is a LandSat image.

frequency bands that span ranges associated with other noise sources since the detection of an event is more involved than simply searching for changes in the amplitude of energy in a particular frequency band.

QuakeMigrate can be fully automated, with results ready for input to location algorithms such as NonLinLoc (Lomax and Virieux, 2000) once suitable detection parameters have been determined. The spectrum-based method, however, requires further phase arrival time picking, as undertaken manually in this study. Additional processing steps could also be undertaken after initial detection using QuakeMigrate that would further improve the performance of QuakeMigrate. One such example could be applying the surface wave dispersion filtering used in the 
spectrum-based method workflow to identify and remove surface crevassing events from the automatically detected QuakeMigrate catalogue. This would obviously enhance the effective removal of crevassing events from the catalogue, although it has not been applied here so as to show the effectiveness of QuakeMigrate in isolation.

The data used in this study have high rates of surface crevassing and other surface noise compared to many other glacial seismology datasets. This dataset therefore provides a particularly challenging dataset within which to search for basal icequakes. QuakeMigrate should therefore provide a useful tool in the search for basal icequakes in other similarly noisy environments such as outlet glaciers of the Greenland ice sheet, alpine glaciers in summer months and fast-moving Antarctic ice streams.

\section{Application of QuakeMigrate for basal icequake detection: limitations}

One limitation of the QuakeMigrate method is the incorrectevent-identification-rate. Only $20 \%$ of the potentially basal icequakes area actually found to be of basal origin after manual phase picking and relocation. However, the incorrect-event-identification-rate is at least partially due to the challenging nature of this dataset. A number of the incorrect event identifications are likely basal icequakes, but with insufficient energy to allow manual picking of arrival times. Poorly located surface crevassing events do not account for every incorrect event identification. When one applies the QuakeMigrate method to a less noisy environment, such as the Rutford Ice Stream dataset, the majority of detected icequakes originate near the bed. This confirms the above hypothesis that the incorrect-event-identification-rate is at least partially due to the low SNR of the Skeidararjökull icequake dataset.

A second limitation of QuakeMigrate is that it does not detect all the basal events. While one can only detect all events above the magnitude of completeness and some events below this, the fact that the spectrum-based method detects some events that QuakeMigrate does not detect is a cause for concern. In an endeavour to detect as many icequakes as possible, the simple argument would be to use both QuakeMigrate and the spectrum-based detection methods. One could also use QuakeMigrate detected events as templates for a cross-correlation template search for further, self-similar events.

A further limitation of QuakeMigrate is that it potentially requires a greater density of receivers than other methods. If some of the receivers have increased noise levels then a higher level of redundancy of receivers is required. The number of stations also affects the overall coalescence value and therefore the choice of detection threshold. Although using a greater number of receivers may initially appear preferable, if they have higher noise levels they could actually have a detrimental impact on the coalescence value and hence on the detection rate. Other methods, such as the spectrum-based method outlined in this study, may not require as many stations to be similarly effective. Unfortunately, these data are too sparse to test this. However, it is an important consideration when deciding what icequake detection method or methods to use, as well as when designing glacial seismology experiments.

While QuakeMigrate provides initial locations, and the results can be immediately relocated in NonLinLoc (Lomax and Virieux, 2000), the hypocentral locations can change significantly when refined. Here, we refine all events $>1$ $\mathrm{km}$ asl, i.e. more than $\sim 200 \mathrm{~m}$ below the ice surface by manually picking the phase arrival times. One could also improve the relative arrival time picks of events in the basal icequake clusters using cross-correlation and double-difference methods (e.g. Waldhauser and Ellsworth (2000); Waldhauser (2001); Schaff and Waldhauser (2005); Waldhauser and Schaff (2008)). The accuracy of arrival time picks is also dictated to some extent by the method used to calculate the onset function. Instead of the STA/LTA function used here, one could enhance the onset function further by using a higher order method such as kurtosis (Langet and others, 2014; Ross and others, 2016). One could also use a more accurate velocity model. Here, we use a homogeneous velocity model. A more accurate velocity model, including firn or lateral variations, would theoretically result in higher coalescence values and hence better detection results. QuakeMigrate allows for 3D velocity models, but for simplicity in this study, we chose to use only a homogeneous velocity model.

There are other earthquake detection methods that have yet to be applied to icequake detection. One method that may have great potential builds on audio recognition algorithms such as Shazam (Wang, 2003). This method, Fingerprint And Similarity Thresholding (FAST) (Yoon and others, 2015), creates fingerprints of the defining features of a signal, groups similar signal fingerprints together and searches for other similar fingerprints, producing an earthquake catalogue (e.g. Yoon and others (2017)). However, this method has not yet been applied in the field of icequake detection and may not work as effectively on noisy icequake datasets. Another method, ConvNetQuake (Perol and others, 2018) uses machine learning techniques for earthquake detection. The method uses convolutional neural networks to optimise a set of filter parameters to discriminate earthquakes from seismic noise for a training dataset. This method therefore is not dependent upon template matching methods and the associated limitations, and according to the authors can detect event types that are not in the training dataset (Perol and others, 2018). The ConvNetQuake could therefore provide a useful icequake detection method if it performs sufficiently well for the typically low SNR events presented in our study.

\section{Additional potential cryoseismology applications}

QuakeMigrate may also be useful for applications using seismicity to study other glacial processes. There are a number of other sources of seismicity within the cryosphere including iceberg calving, collision and grounding, englacial hydrofracture, hydrologically induced glacial tremor and ice shelf rifting (Podolskiy and Walter, 2016; Aster and Winberry, 2017). If the respective source radiates sufficient energy to arrive at multiple receivers locally, and if the source can be approximated as radiating from a point source or small region relative to the network of receivers, then QuakeMigrate may detect the event. Theoretically, QuakeMigrate could also potentially be used to investigate the origin of glacial tremor. However, glacial tremor can be sufficiently long in duration that a distinct packet of energy is impossible to back migrate (e.g. Roeoesli and others (2016)), a crucial criterion for the QuakeMigrate method. 


\section{CONCLUSIONS}

Icequakes at or near the ice/bed interface of a glacier have the potential to be used to study the interaction of ice with the underlying till or bedrock. This is important for constraining processes such as basal sliding of glaciers and ice streams. We present a method of automatically detecting and discriminating between these basal icequakes and surface crevassing. The QuakeMigrate method introduced here involves searching through time and space for the coalescence of energy from these events. Data from Skeidararjökull, an outlet glacier of the Vatnajökull Ice Cap, SE Iceland, show that the QuakeMigrate method is effective in finding basal icequakes and automatically discriminating them from surface crevassing events. The QuakeMigrate method is also found to outperform a spectrum-based method. A higher number of basal icequakes are detected (27 vs. 6), the incorrect-event-identificationrate of basal icequake detections relative to surface crevassing and other seismic sources is lower (80 vs. $97 \%$ incorrect-event-identification-rate), and the QuakeMigrate method detects an additional, spatially independent and previously undiscovered basal icequake cluster. We also confirm that the events originate deep inside the ice by using a variety of measures including $V_{p} / V_{s}$ ratios, particle motions and dispersion characteristics. Although QuakeMigrate has limitations, such as the high incorrectevent-identification-rate and it misses some events, these limitations have been shown to be less significant for more typical, less noisy icequake datasets. Software implementing both the QuakeMigrate and the spectrum-based methods are released to provide a tool for the cryoseismology community.

\section{ACKNOWLEDGEMENTS}

We thank Julian Drew for contributions to the development of the QuakeMigrate software. The QuakeMigrate software is made freely available for research use and can be found on online (https://github.com/Ulvetanna/QuakeMigrate). The spectrum-based method software, SpectDetect, is also made freely available for research use and can be found on GitHub (https://github.com/TomSHudson/SpectDetect) and is available on the Python repository. Users of this software should acknowledge this paper and ?, if appropriate. We thank Hunter Philson for helping collect the Skeidararjökull data and Robert Green for helping preprocess it. We thank Finnur Pálsson and the University of Iceland Glaciology Group for the Skeidararjökull surface and bed topography. We thank Andy Smith for leading the Rutford Ice Stream project, Hamish Pritchard for collecting the Rutford data and Emma Smith for help deciding on initial QuakeMigrate detection parameters to use. We thank Fabian Walter and his group for their contribution to a practical icequake detection session at the POLENET Glacial Seismology Training School (2017), upon which certain aspects of the spectrumbased method are based. We also thank the reviewers for constructive feedback that helped improve this study. Tom Hudson was funded by a the Cambridge Earth System Science NERC Doctoral Training Partnership. The Skeidararjökull data collection was funded by a BAS innovation grant and NERC Geophysical Equipment Facility Loan 1022. The Rutford data collection was funded by NERC grant NE/B502287/1 and NERC Geophysical
Equipment Facility Loan 852. University of Cambridge, Department of Earth Sciences contribution number 4390.

\section{REFERENCES}

Aki K and Richards PG (2002) Quantitative seismology. Geology (University Science Books) Seismology, University Science Books, ISBN 9780935702965

Allen RV (1978) Automatic earthquake recognition and timing from single traces. Bull. Seismol. Soc. Am., 68(5), 1521-1532

Allstadt K and Malone SD (2014) Swarms of repeating stick-slip icequakes triggered by snow loading at Mount Rainier volcano. J. Geophys. Res. Earth Surf., 119(5), 1180-1203, ISSN 21699003 (doi: 10.1002/2014JF003086)

Aster RC and Winberry JP (2017) Glacial seismology. Rep. Prog. Phys., 80(12), 126801, ISSN 0034-4885 (doi: 10.1088/13616633/aa8473)

Björnsson $\mathrm{H}$ (2017) The glaciers of iceland. Atlantis Press, Paris, ISBN 978-94-6239-206-9 (doi: 10.2991/978-94-6239-207-6)

Carmichael JD, Pettit EC, Hoffman M, Fountain A and Hallet B (2012) Seismic multiplet response triggered by melt at Blood Falls, Taylor Glacier, Antarctica. J. Geophys. Res. Earth Surf., 117(3), 1-16, ISSN 21699011 (doi: 10.1029/2011JF002221)

Dixon JP, Power JA and Stihler SD (2005) A comparison of seismic event detection with IASPEI and Earthworm acquisition systems at Alaskan volcanoes. Seismol. Res. Lett., 76(2), 168-176, ISSN 08950695 (doi: 10.1785/gssrl.76.2.168)

Drew J, White RS, Tilmann F and Tarasewicz J (2013) Coalescence microseismic mapping. Geophys. J. Int., 195(3), 1773-1785, ISSN 0956540X (doi: 10.1093/gji/ggt331)

Helmstetter A and Garambois S (2010) Seismic monitoring of Schilienne rockslide (French Alps): Analysis of seismic signals and their correlation with rainfalls. J. Geophys. Res. Earth Surf., 115(3), 1-15, ISSN 21699011 (doi: 10.1029/2009JF001532)

Helmstetter A, Moreau L, Nicolas B, Comon P and Gay M (2015) Intermediate-depth icequakes and harmonic tremor in an Alpine glacier (Glacier d'Argentière, France): Evidence for hydraulic fracturing. J. Geophys. Res. Earth Surf., 120(3), 402416, ISSN 21699011 (doi: 10.1002/2014JF003289)

Jones GA, Kulessa B, Doyle SH, Dow CF and Hubbard A (2013) An automated approach to the location of icequakes using seismic waveform amplitudes. Ann. Glaciol., 54(64), 1-9, ISSN 02603055 (doi: 10.3189/2013AoG64A074)

Keilis-Borok V (1989) Seismic surface waves in a laterally inhomogeneous Earth. Modern Approaches in Geophysics, Kluwer Academic Publishers, Dordrecht, Boston, ISBN 978-94-0090883-3

King EC, Pritchard HD and Smith AM (2016) Subglacial landforms beneath Rutford Ice Stream, Antarctica: detailed bed topography from ice-penetrating radar. Earth Syst. Sci. Data, 8(1), 151-158, ISSN 18663516 (doi: 10.5194/essd-8-151-2016)

Langet N, Maggi A, Michelini A and Brenguier F (2014) Continuous kurtosis-based migration for seismic event detection and location, with application to Piton de la Fournaise volcano, La Réunion. Bull. Seismol. Soc. Am., 104(1), 229-246, ISSN 00371106 (doi: 10.1785/0120130107)

Lomax A and Virieux J (2000) Probabilistic earthquake location in 3D and layered models. Advances in Seismic Event Location, Volume 18 of the series Modern Approaches in Geophysics, 101-134

Mikesell TD and 5 others (2012) Monitoring glacier surface seismicity in time and space using Rayleigh waves. J. Geophys. Res. Earth Surf., 117(2), 1-12, ISSN 21699011 (doi: 10.1029/ 2011JF002259)

Morlighem M and 5 others (2010) Spatial patterns of basal drag inferred using control methods from a full-Stokes and simpler models for Pine Island Glacier, West Antarctica. Geophys. Res. Lett., 37(14), 1-6, ISSN 00948276 (doi: 10.1029/ 2010GL043853) 
Murray T, Smith AM, King MA and Weedon GP (2007) Ice flow modulated by tides at up to annual periods at Rutford Ice Stream, West Antarctica. Geophys. Res. Lett., 34(18), 6-11, ISSN 00948276 (doi: 10.1029/2007GL031207)

O'Neel S, Marshall HP, McNamara DE and Pfeffer WT (2007) Seismic detection and analysis of icequakes at Columbia Glacier, Alaska. J. Geophys. Res. Earth Surf., 112(3), 1-14, ISSN 21699011 (doi: 10.1029/2006JF000595)

Perol T, Gharbi M and Denolle M (2018) Convolutional neural network for earthquake detection and location. Sci. Adv., 4, 1-8, ISSN 2375-2548 (doi: 10.1126/sciadv.1700578)

Podolskiy EA and Walter F (2016) Cryoseismology. Rev. Geophys., 54, 1-51 (doi: 10.1002/2016RG000526)

Ritz C and 5 others (2015) Potential sea-level rise from Antarctic icesheet instability constrained by observations. Nature, 528(7580), 115-118, ISSN 14764687 (doi: 10.1038/nature16147)

Roeoesli C, Walter F, Ampuero JP and Kissling E (2016) Seismic moulin tremor. J Geophys Res Solid Earth, 121(8), 5838-5858, ISSN 21699313 (doi: 10.1002/2015JB012786)

Röösli C and 6 others (2014) Sustained seismic tremors and icequakes detected in the ablation zone of the Greenland Ice Sheet. J. Glaciol., 60(221), 563-575, ISSN 00221430 (doi: 10.3189/2014joG13j210)

Ross ZE, White MC, Vernon FL and Ben Zion Y (2016) An improved algorithm for real-time s-wave picking with application to the (Augmented) ANZA network in Southern California. Bull. Seismol. Soc. Am., 106(5), 2013-2022, ISSN 19433573 (doi: 10.1785/0120150230)

Schaff DP and Waldhauser F (2005) Waveform cross-correlationbased differential travel-time measurements at the northern California seismic network. Bull. Seismol. Soc. Am., 95(6), 2446-2461, ISSN 00371106 (doi: 10.1785/0120040221)

Smith E, Smith A, White R, Brisbourne A and Pritchard H (2015) Mapping the ice-bed interface characteristics of Rutford Ice Stream, West Antarctica, using microseismicity. J. Geophys. Res. Earth Surf., 120(9), 1881-1894, ISSN 21699003 (doi: 10.1002/2015JF003587)

Thelen WA and 5 others (2013) Shallow repeating seismic events under an alpine glacier at Mount Rainier, Washington, USA. J. Glaciol., 59(214), 345-356, ISSN 00221430 (doi: 10.3189/ 2013JoG12J111)

Wadati K (1933) On the travel time of earthquake waves. (Part II). J. Meteorol. Soc. JPN, II(11.1), 14-28 (doi: http://doi.org/10.2151/ jmsj1923.11.114)

Waldhauser F (2001) HypoDD - A Program to Compute DoubleDifference Hypocenter Locations by. US Geol. Surv. Open File Rep. 01-113,1-25 (doi: http://doi.org/10.3133/ofr01113)

Waldhauser F and Ellsworth W (2000) A double-difference earthquake location algorithm: method and application to the Northern Hayward Fault, California. Bull. Seismol. Soc. Am. 90(6), 1353-1368, ISSN 0037-1106 (doi: 10.1785/0120000006)

Waldhauser F and Schaff DP (2008) Large-scale relocation of two decades of Northern California seismicity using cross-correlation and double-difference methods. J. Geophys. Res. Solid Earth, 113 (8), 1-15, ISSN 21699356 (doi: 10.1029/2007JB005479)

Wang ALC (2003) An industrial strength audio search algorithm. In Proceedings of the 4th International Society for Music Information Retrieval Conference, Baltimore, Maryland (USA), 713-718, ISBN 2974619401 (doi: 10.1109/IITAW.2009.110)

Withers $\mathrm{M}$ and 6 others (1998) A comparison of select trigger algorithms for automated global seismic phase and event detection. Bull. Seismol. Soc. Am., 88(1), 95-106, ISSN 00371106

Yoon CE, O'Reilly O, Bergen KJ and Beroza GC (2015) Earthquake detection through computationally efficient similarity search. Sci. Adv., 1(11), 1-13 (doi: 10.1126/sciadv.1501057)

Yoon CE, Huang Y, Ellsworth WL and Beroza GC (2017) Seismicity during the initial stages of the Guy-Greenbrier, Arkansas, earthquake Sequence. J Geophys Res Solid Earth, 122(11), 92539274, ISSN 21699356 (doi: 10.1002/2017JB014946)

\section{APPENDIX A. CHOICE OF NONLINLOC FILTER PARAMETERS FOR THE QUAKEMIGRATE CATALOGUE OF EVENTS}

As QuakeMigrate provides uncertainty estimates for the phase arrival times of energy from the icequakes, one can use the statistical measures calculated by NonLinLoc (Lomax and Virieux, 2000) to filter likely incorrectly identified events. Here, we use a combination of the square of the uncertainty in vertical location, $\sigma_{z}^{2}$, and the root-meansquare time residual, $t_{\mathrm{rms}}$, a measure of the overall timing uncertainty of an event. As QuakeMigrate provides realistic estimates of arrival time errors, $\sigma_{z}^{2}$ and $t_{\mathrm{rms}}$ are therefore realistic physical quantities.

To determine the values of $\sigma_{z}^{2}$ and $t_{\mathrm{rms}}$ used to filter the results, we look at the relationship of the parameters with the depth of events, as one would expect these physical measures of event location uncertainty to be related to the depth of an icequake. The results for all the QuakeMigratedetected events in this study are plotted in Fig. 9. A significant number of crevassing events can be seen at $1.2 \mathrm{~km}$ asl. Ignoring these values, a trend can be seen where $\sigma_{z}^{2}$ values are lower near the ice surface $(\sim 1.2 \mathrm{~km}$ asl) and the icebed interface, where one might expect the majority of icequake seismicity to occur. The higher values of $\sigma_{z}^{2}$ for automatically detected events at intermediate depth within the ice are likely to be due to either: the events are surface crevassing or basal icequakes that, within uncertainty, lie at the ice surface or the ice/bed interface; or they are indeed intermediate depth events, and just have smaller amplitudes than surface crevassing or basal icequakes, leading to higher uncertainties in automatically detected phase arrival times and therefore higher location uncertainties. It is also possible to observe an approximate trend of $\sigma_{z}^{2}$ with $t_{\mathrm{rms}}$, with lower $t_{\mathrm{rms}}$ value events following the aforementioned trend of $\sigma_{z}^{2}>0.075 \mathrm{~km}^{2}$ with depth. From this data, we therefore decided that events with (corresponding to events with depth uncertainties of $>275 \mathrm{~m}$ ) and $t_{\mathrm{rms}}>0.025 \mathrm{~s}$ are likely to be incorrect event identifications or at least events of such low amplitude that further analysis would not be possible.

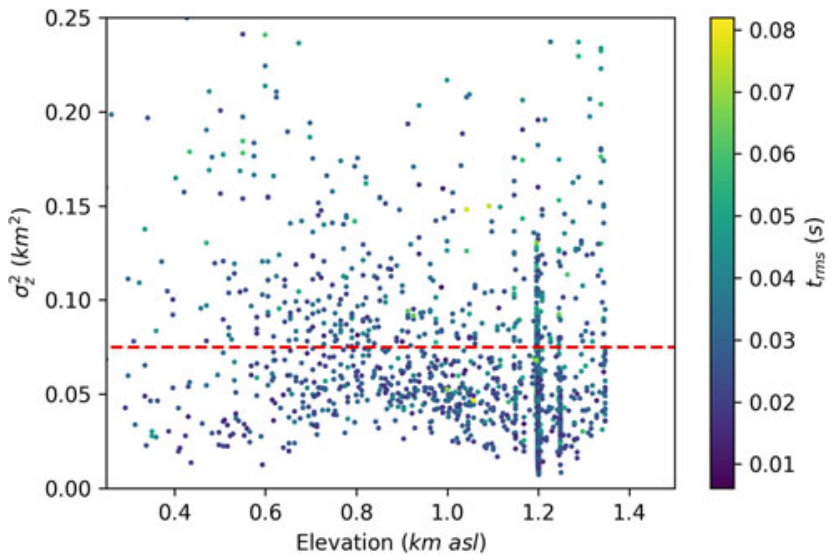

Fig. 9. Plot of $\sigma_{z}^{2}$ against elevation asl, for the events detected by QuakeMigrate. Events are coloured by $t_{\mathrm{rms}}$. 
APPENDIX B. QUAKEMIGRATE PARAMETERS FOR RUTFORD ICE STREAM ICEQUAKE SEARCH

Table 4 gives the parameters used for detecting icequakes at Rutford Ice Stream, Antarctica, plotted in Fig. 8. Some of these settings are based on those used in Smith and others (2015).

Table 4. Table of specific QuakeMigrate parameters used in the detection of icequakes at the Rutford Ice Stream, West Antarctica

\begin{tabular}{ll}
\hline Parameter & \multicolumn{1}{c}{ Value } \\
\hline Frequency filter, P & $20-200 \mathrm{~Hz}$ \\
Frequency filter, S & $10-120 \mathrm{~Hz}$ \\
Seismic velocity, P & $3841 \mathrm{~m} \mathrm{~s}^{-1}$ \\
Seismic velocity, S & $1970 \mathrm{~m} \mathrm{~s}^{-1}$ \\
Grid resolution & $x=100 \mathrm{~m}$ \\
& $y=100 \mathrm{~m}$ \\
STA/LTA, P & $z=100 \mathrm{~m}$ \\
STA/LTA, S & $0.01 \mathrm{~s} / 0.25 \mathrm{~s}$ \\
Coalescence detection threshold & $0.05 \mathrm{~s} / 0.5 \mathrm{~s}$ \\
Moving time window (marginal window) & 1.75 \\
Pre/post padding around window & $0.75 \mathrm{~s}$ \\
NonLinLoc event relocation filter parameters: & $1.0 \mathrm{~s}$ \\
$\sigma_{z}^{2}$ & \\
$t_{\text {rms }}$ & $0.075 \mathrm{~km}^{2}$ \\
\end{tabular}

